\section{Autoantikörper gegen RA33}

W. Stöcker und W. Schlumberger

Euroimmun Medizinische Labordiagnostika AG, Lübeck, Deutschland

Synonym(e) Anti-A2/RA33; RA33-Antikörper

Englischer Begriff anti-RA33 antibodies; autoantibodies to A2 core protein of heterogeneous nuclear ribonucleoprotein complexes (A2-hnRNP)

Definition Antikörper gegen das A2-Core-Protein heterogener nukleärer Ribonukleoprotein-Komplexe (A2-hnRNP).

Probenstabilität Autoantikörper sind bei $+4{ }^{\circ} \mathrm{C}$ bis zu 2 Wochen lang beständig, bei $-20^{\circ} \mathrm{C}$ über Monate und Jahre hinweg.

Analytik Autoantikörper gegen RA33 lassen sich mit einem - Enzymimmunoassay unter Verwendung nativer oder rekombinanter Antigene nachweisen.
Referenzbereich - Erwachsene Negativ.

Referenzbereich - Kinder Negativ.

Indikation Evtl. bei Verdacht auf rheumatoide Arthritis, aber geringer diagnostischer Nutzen.

Diagnostische Wertigkeit Autoantikörper gegen RA33 kommen bei etwa einem Drittel der Patienten mit rheumatoider Arthritis vor. Ihre Spezifität ist eingeschränkt, da sie auch bei Patienten mit SLE und anderen Erkrankungen des rheumatischen Formenkreises auftreten.

\section{Literatur}

Lee YH, Bae SC (2016) Diagnostic accuracy of anti-Sa and anti-RA33 antibodies in rheumatoid arthritis: a meta-analysis. Z Rheumatol 76:535. https://doi.org/10.1007/s00393-016-0134-y

Steiner G, Smolen J (2002) Autoantibodies in rheumatoid arthritis and their clinical significance. Arthritis Res 4(Suppl 2):1-5 